9. Shokalo, M. (2018). Andrii Zholdak shokuvav Berlin [Andrii Zholdak shocked Berlin], [online] Available at:〈http://www.bbc.com/ukrainian/entertainment/story/2005/11/051117_shokalo_zholdak.shtml> [Accessed 14.06.2018].

(C) Гапчук Ю. О., 2018

Стаття надійшла до редакиіï: 31.08 .2018

УДК 7.017+7.038.3](477)

\author{
Доколова Альона Сергї̈на \\ аспірантка, \\ Київський національний університет \\ культури і мистеитв, \\ вул. С. Коновальия,36, Київ, Україна, 01133, \\ https://orcid.org/0000-0003-3795-6789 \\ dokolashka@gmail.com
}

\title{
ВИКОРИСТАННЯ НОВІТНІХ ТЕХНОЛОГІЙ 3D МАРРІNG В УКРАЇНІ
}

Мета дослідження - здійснити комплексний аналіз історії становлення технології 3D Mapping (відеомеппінг) в Україні та особливостей іï використання. Застосовано такі методи дослідження: аналіз, синтез, історично-порівняльний (для висвітлення історії становлення 3D Mapping в Україні та вивчення українських i зарубіжних мультимедійних проектів), мистецтвознавчий (для розгляду особливостей використання 3D Mapping). Наукова новизна статті полягає у виявленні можливостей використання 3D Mapping як новітньої технології в різних культурно-мистецьких сферах. 3D Mapping досліджено як продовження технології “chromakey", яка широко використовується в сучасному кінематографі. Здійснено прогноз стосовно перспектив використання 3D Mapping в мистецтві та рекламі. Висновки. Доведено, що еволюція екранного мистецтва 3 кінця XX ст. відбувається під впливом аудіовізуальних технологій, 3D Mapping. Сучасний етап його розвитку характеризується інтеграцією та синтезом різних засобів і технологій інформаційно-технічного прогресу в культурі i мистецтві. Використання художньо-технологічного аспекта в сценарно-режисерському вирішенні заходу $є$ запорукою його успіху та глядацької симпатії, що знаходить відображення у художньо-естетичній свідомості.

Ключові слова: 3D Mapping; екранне мистецтво; “chromakey”; аудіовізуальні твори; сценографія; відеопроекція.

Доколова Алёна Сергеевна, аспирант, Киевский национальный университет культуры и искусств, ул. Е. Коновальиа, 36, Киев, Украина

Использование новых технологий 3D Mapping в Украине

Цель исследования - провести комплексный анализ истории становления технологии 3D Mapping (видеомеппинг) в Украине и особенностей ее использования. Применены такие методы исследования: анализ, синтез, историко-сравнительный (для освещения истории становления 3D Mapping в Украине и изучения украинских и зарубежных мультимедийных проектов), искусствоведческий (для рассмотрения особенностей использования 3D Mapping). Научная новизна статьи заключается в выявлении возможностей использования 3D Mapping как новейшей технологии в различных культурно-художественных сферах. 3D Mapping исследовано как продолжение технологии “chromakey", которая широко используется в современном кинематографе. Осуществлен прогноз относительно перспектив применения 3D Mapping в искусстве и рекламе. Выводы. Доказано, что эволюция экранного искусства с конца XX в. происходит под влиянием аудиовизуальных технологий, 3D 
Mapping. Современный этап его развития характеризуются интеграцией и синтезом разных средств и технологий информационно-технического прогресса в культуре и искусстве. Использование художественно-технологического аспекта в сценарно-режиссерском решении мероприятия является залогом его успеха и зрительской симпатии, что находит отображение в художественно-эстетическом сознании.

Ключевые слова: 3D Mapping; экранное искусство; “chromakey”; аудиовизуальные произведения; сценография; видеопроекция.

Dokolova Aliona, Postgraduate, Kyiv National University of Culture and Arts, 36, Y. Konovaltsia St, Kyiv, Ukraine

New 3D Mapping technologies application in Ukraine

The purpose of the article is to carry out a comprehensive analysis of the history of development of the 3D mapping technology in Ukraine and the peculiarities of its use. The research methodology. The following research methods were applied: analysis, synthesis, historical and comparative (for highlighting the history of development of 3D mapping in Ukraine and investigating Ukrainian and foreign multimedia projects), and artistic (for studying the features of using 3D mapping). The scientific novelty of the work lies in defining the opportunities of using 3D mapping as a modern technology in various cultural and artistic spheres. 3D mapping is researched as a continuation of the "chromakey" technology, which is widely used in contemporary cinematography. The forecast is made concerning the prospects of using 3D mapping in the fields of art and advertising. Conclusions. It was proved that the evolution of screen arts since the end of the $20^{\text {th }}$ century has been taking place under the influence of audiovisual technologies and 3D mapping. The modern stage of its development is characterized by integration and synthesis of various means and technologies of information and technological progress in culture and art. The use of the artistic and technological aspect in the scriptwriting and directorial solution of the event is a guarantee of its success and appeal, which is reflected in artistic and aesthetic consciousness. projection.

Key words: 3D Mapping; screen arts; "chromakey”; audiovisual works; scenography; video

Вступ. Технічний прогрес XX ст. наклав свій відбиток на свідомість і різні аспекти життя людства, не оминувши культуру й мистецтво. Досягнення, що впроваджуються в ці сфери, розширюють можливості традиційних напрямів творчості і сприяють появі нових видів мистецтва та жанрів, інтегруючих можливості інформаційних технологій.

Інтегрована художня культура завдяки широкому спектру засобів виразності (аудіовізуальні, телекомунікаційні, мультимедійні технології) здатна здійснювати суттєвий вплив на формування масової культури, іiї смаків та орієнтацій. Нині домінуючим явищем стає екранна культура, до якої входять, за спостереженнями Ю. Усова, «різні аудіовізуальні вистави, комп'ютерні технології, електронні мистецтва, фільми-концерти, відеокліпи, котрі охоплюють побут, художню діяльність і дозвіллєві форми аматорської творчості в аудіовізуальній сфері» (Усов, 1995, с. 28).

Одним із сучасних напрямів аудіовізуального мистецтва $€$ 3D Mapping (3-вимірне відображення, проектування), що становить проекцію на фізичний об'єкт навколишнього середовища з урахуванням його геометрії і розташування в просторі.

Дослідницька база з вивчення візуального мистецтва в Україні сьогодні перебуває в зародковому стані, поодинокими $є$ і наукові роботи з означеної проблеми. Серед праць, присвячених дослідженню 3D Mapping, варто відмітити статтю О. Кліщ «Особливості використання світлових проекцій на об'єктах міського середовища» (Кліщ, 2014).

Мета статті - здійснити комплексний аналіз історії становлення технології 3D Mapping в Україні та особливостей іï використання; розглянути технічні і культурні аспекти розвитку технології 3D Mapping в Україні як еволюції екранного мистецтва. Для реалізації мети визначено такі завдання: з'ясувати історію становлення 3D Mapping; дослідити українські та зарубіжні мультимедійні проекти, засновані на технології 3D Mapping. 
Виклад основного матеріалу. Еволюція мультимедійного аудіовізуального мистецтва пройшла складний процес становлення взаємодії технічних засобів і творчих задумів автора. Проаналізуємо розвиток екранного мистецтва та аудіовізуальної культури на базі досліджень К. Розлогова, К. Коліна, Н. Хилько. В основі виділення етапів становлення екранного мистецтва і культури лежать технічні артефакти, що обумовлюють процес формування і поширення артефактів культурних - творів екранних мистецтв.

Біля витоків екранного мистецтва стояло німе кіно, яке сприяло лише візуалізації задумів авторів. Період же аудіовізуального синтезу пов'язаний з винаходом звукозапису і мультиплікації та їх уведенням у кінематограф, що й послужило поштовхом для становлення екранної культури і власне кіномистецтва. Цей період також характеризується взаємодією кінематографа з різними формами театральних видовищ і вистав.

3 розвитком технічних засобів екранної культури поряд з використанням традиційних музичних інструментів відбувалося впровадження більш складних механізмів створення аудіовізуальних творів.

Монтаж, комп'ютерні спецефекти, зйомка окремих епізодів за допомогою відеотехніки, упровадження аналогово цифрового перетворення - усе це знаменує початок електронної революції як специфічного етапу розвитку аудіовізуальної-екранної культури. Для цього етапу характерне виникнення естетики телебачення, що базується на відеоефектах.

Можливості нових засобів комунікації, пов’язаних з появою комп'ютера, ініціювали процеси глобалізації культури, що сприяло об'єднанню різних технічних форм аудіовізуальної комунікації і мистецтва. Інтернет і глобальні мережі змінили характер спілкування між людьми: змінилися ідеологічні пріоритети, стиль i темп життя. Інтерактивність стає найважливішим складником актуальної художньої діяльності. Елементи інтерактивності виникають на телебаченні, у відео та комп'ютерних іграх, у виробничих процесах підготовки аудіовізуальних творів, з'являються технології віртуальної реальності. Отже, на початку XXI ст. настав період конвергенції всіх форм аудіовізуального в екранному мистецтві.

Осмислюючи екранну культуру, В. Познін зазначає, що «в цей час завершується четвертий етап іiі еволюції (після появи кіно, упровадження в нього звуку, кольору та експериментів з формами екрана), етап атракціонів, залучення публіки видовищністю завдяки використанню новітніх технічних засобів і технологій» (Познин, 2008, с. 427). Під час аналізу сучасного періоду розвитку аудіовізуального екранного мистецтва потрібно відзначити, що сьогодні стало можливим здійснювати складні просторово-графічні світлові проекції, поєднуючи їх із музикою, орієнтуючись на образну єдність, синтез музики i барвистої картинки. У масових мультимедійних шоу нині широко застосовуються лазерні ефекти, здатні проектувати різні зображення на сцені, стінах, воді та інших поверхнях.

Ще одним вектором розвитку екранної культури можна вважати мультимедійну сценографію, тобто використання технологій мультимедіа та засобів комп'ютерної графіки. Має рацію Л. Михайлов: «Голографічна проекція, chromakey (рис. 1) - технологія «прорізання» за кольором (застосовується тепер переважно в кінематографі і на телебаченні), упровадження мобільних технологій з метою створення атмосфери інтерактивності участі в дійстві кожного глядача - ось елементи сценографії завтрашнього дня» (Михайлов, 2007, с. 13).

Голографічна проекція - основа технології 3D Mapping (відеомеппінг або проекційне шоу). Вона становить «інтеграцію відеомистецтва і 3D-технологій, що полягає у створенні 3D Mapping на фізичний об'єкт навколишнього середовища з урахуванням його геометрії та розташування у просторі, при художній модифікації якої за допомогою аудіовізуальних засобів у глядача виникає аудіовізуальна ілюзія» (Мальцева, 2013, с. 96).

Використання новітніх аудіовізуальних технологій у поєднанні 3 яскравою художньою ідеєю дає змогу авторам утримувати зацікавленість глядача, сприяє посиленню естетичного і психоемоційного ефекту, відіграє культурологічну роль у розвитку жанру масового мультимедійного шоу. Звернемося до сучасних інсталяцій, які використовують 
технологію відеомеппінгу для створення неповторного образу, декорацій та аудіовізуальної ілюзії для глядача.

Для проведення якісної оцінки мультимедійних творів треба зупинитися на аспектах, що впливають на загальне враження аудиторії. Основоположним у створенні і демонстрації таких творів мистецтва є технічний супровід, до складу якого входять: професійне звукове та світлове обладнання, проектори високого рівня яскравості, медіасервери і різні контролери. Технічне оснащення залежить, насамперед, від місця проведення (площі проекції) та кількості глядачів. Так, на відкритті зимових олімпійських ігор у Сочі під час проведення театралізованого шоу було використано 120 проекторів і понад 2,5 млн. ламп. Відповідно на чим більші масштаби розрахована інсталяція, тим більша кількість апаратури і їі потужність потрібні. При цьому поділяють на об’єктивний, просторовий, середовищний, фасадний і ландшафтний меппінг.

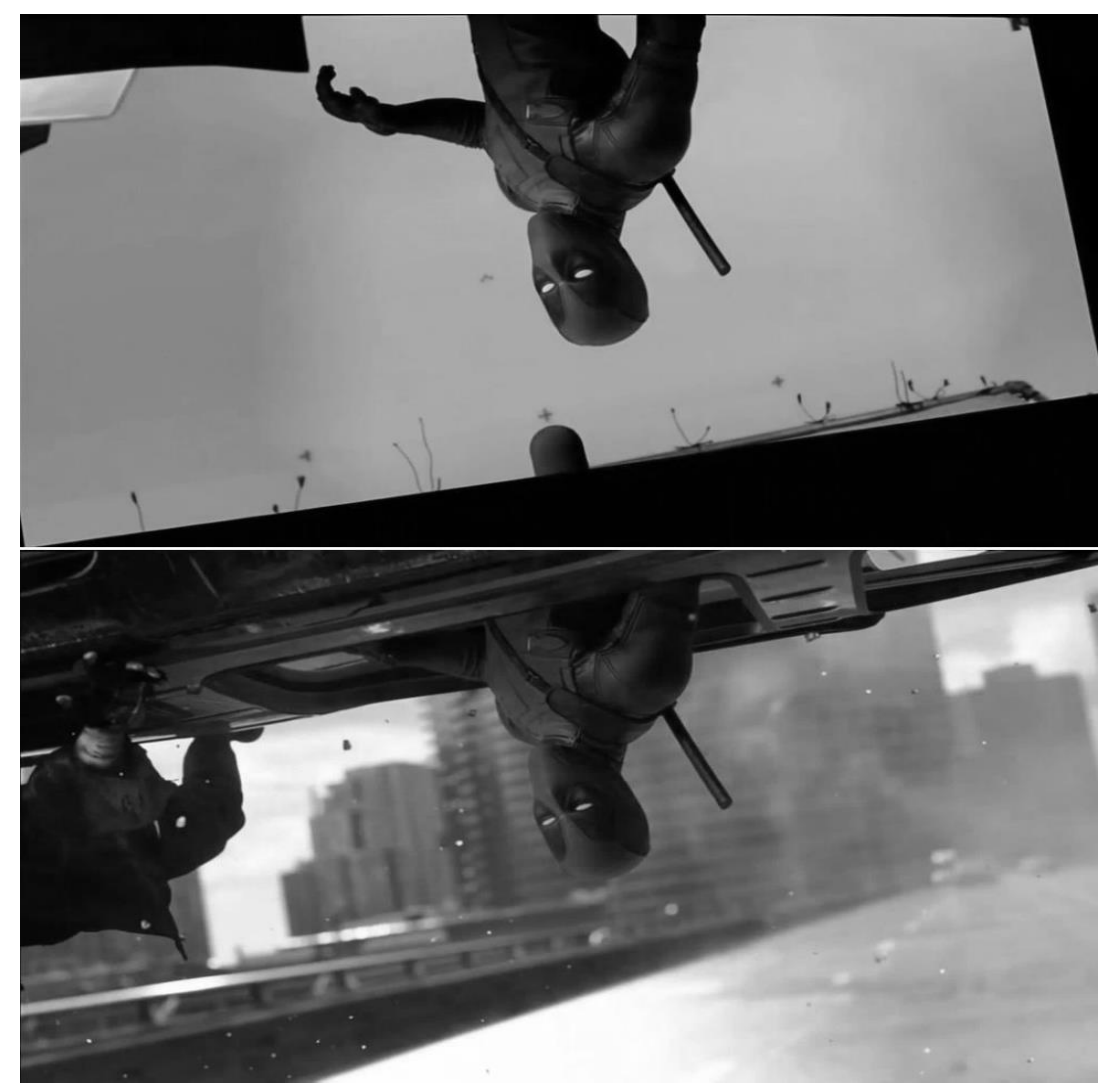

Рисунок 1. Використання технології “chromakey” на зйомках фільму «Дедпул»: під час зйомок (зверху) та після монтажу (знизу)

Figure 1. Using the "chromakey" technology on "Deadpool" movies: during shooting (top) and after installation (bottom)

Не залишається без уваги і контент, тобто змістовний складник твору; у цьому плані можливі кілька варіантів: сюжетно-режисерська постановка, підкріплена сукупністю аудіовізуальних художньо-виразних засобів, або просто набір красивих емоційновидовищних сцен. Над цим компонентом працюють режисери-постановники i 3D Mapping відповідно до вимог замовника.

Вибір художньо-виразних засобів пов'язаний із напрямом, у якому застосовується технологія 3D Mapping. Нерідко вони доповнюються інтерактивними формами взаємодії з людиною: можливістю контакту відеопроекції та учасника шоу, впливом глядача на те, як відбувається дія та ін.

Розглянемо сучасні українські мультимедійні проекти, засновані на технології 3Dвідеомеппінгу. Можна вважати, що відеомеппінг з'явився на основі комп'ютерного меппінгу, котрий використовується в дизайні відеоігор, у створенні 3D-архітектури, фото-, відео- і лазерних проекцій, а також аудіовізуальних шоу. Але, на відміну від комп’ютерного 
меппінгу, який робить об'ємними двовимірні зображення, у відеомеппінгу реальні об'єкти стають чимось віртуальним, рухомим, інтерактивним. Це новий вид проекцій на архітектуру, що набув особливої популярності під час масштабних масових святкувань. Його особливість полягає в тому, що споруду, на яку виконується проекція, можна змінити абсолютно чи створити ілюзію деформування фасаду, у такий спосіб зазирнувши в середину. Реалізація такого роду проекту потребує використання певного обладнання:

- програмне забезпечення - пульт управління;

- відеосервери (кількість обумовлюється масштабом проекту);

- проекційне обладнання (потужність проекторів залежить від розміру засвічуваного об’єкта);

- акустичні системи;

- додатково можуть застосовуватись лазери та зовнішні спецефекти (Ландер, 2012, c. 51).

Крім цього, проект потрібно затвердити в державних інстанціях, це допоможе впевнитися у відсутності аморального наповнення сюжету. На початку розвитку цього виду мистецтва від авторів очікувалась демонстрація можливостей апаратури; сьогодні ж кращі творіння нагадують театральні постановки, в яких використаний складний сценарій, сюжетні ходи та глибокий зміст.

Саме таким можна назвати проект освітлення статуї «Батьківщина-мати» в Києві (рис. 2), який презентував палітру українських національних костюмів.

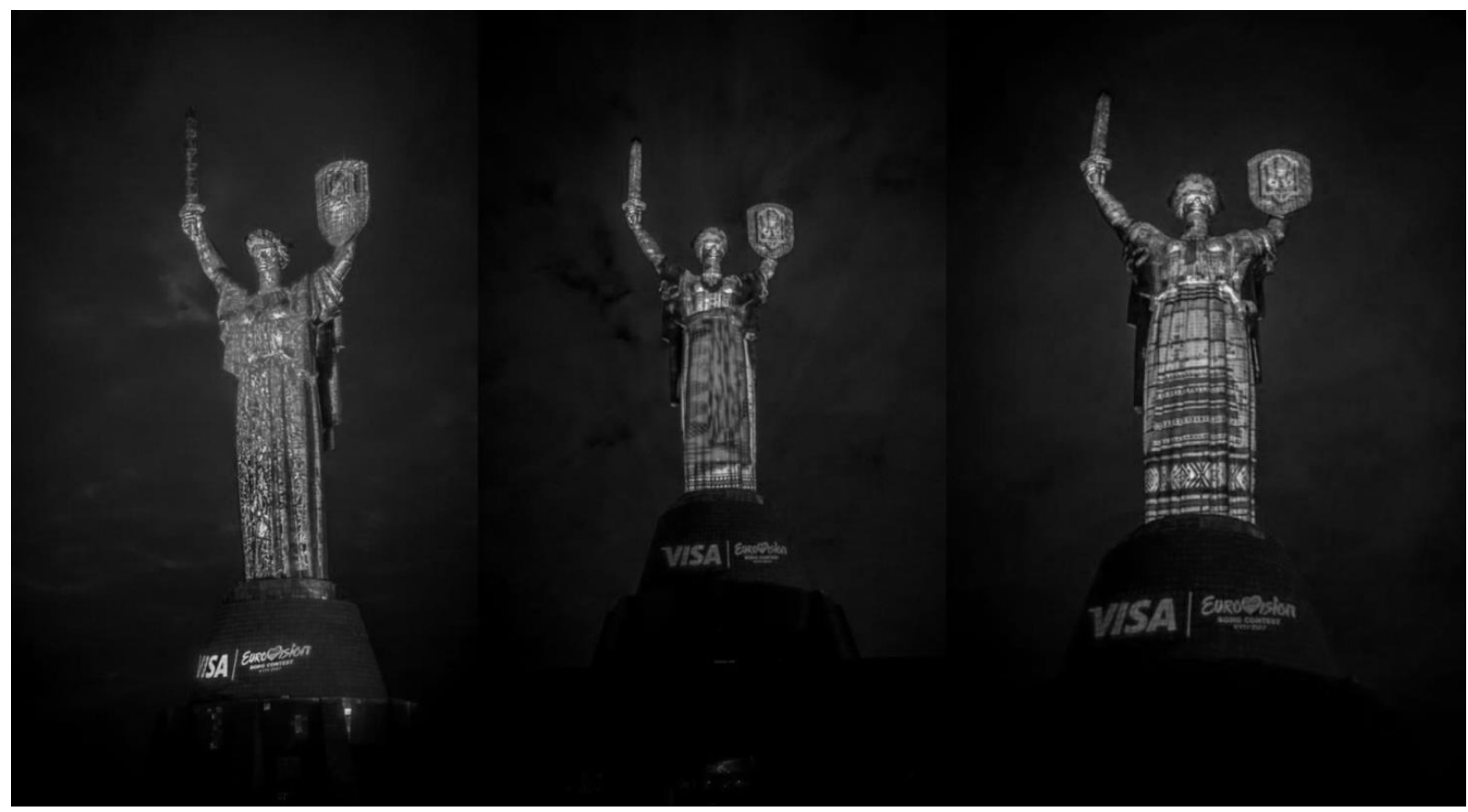

Рисунок 2. 3D Mapping на статуї «Батьківщина-мати» в Києві Figure 2. 3D Mapping on the statue of "motherland" in Kiev

Проект було приурочено до конкурсу «Євробачення - 2017». Для святкового вбрання організатори відібрали такі візерунки й моделі вишиванок, які продемонстрували особливість та автентичність української культури різних регіонів. Показ потрапив до Книги рекордів України як «найвищий 3D Mapping на монументальній скульптурі «Батьківщинамати».

Незабутнє шоу подарували мешканцям Краматорська співробітники українськоросійської компанії «Рromo-promin», що засвідчує відео, демонструючи потужні можливості цієї нової, але вельми захоплюючої технології. ${ }^{1}$

\footnotetext{
${ }^{1}$ http://www.promo-promin.com/portfolio/item/99/
} 
ISSN 2410-1176 (Print) Вісник КНУКіМ. Серія Мистецтвознавство. Вип. 39. ISSN 2616-4183 (Online)

Краще зрозуміти, як саме працює технологія, можна ознайомившись із технічним завданням, які постають перед учасниками вже традиційного в Україні конкурсу із 3D Mapping, котрий проводиться в рамках Київського фестивалю світла “KLF” (рис. 3).

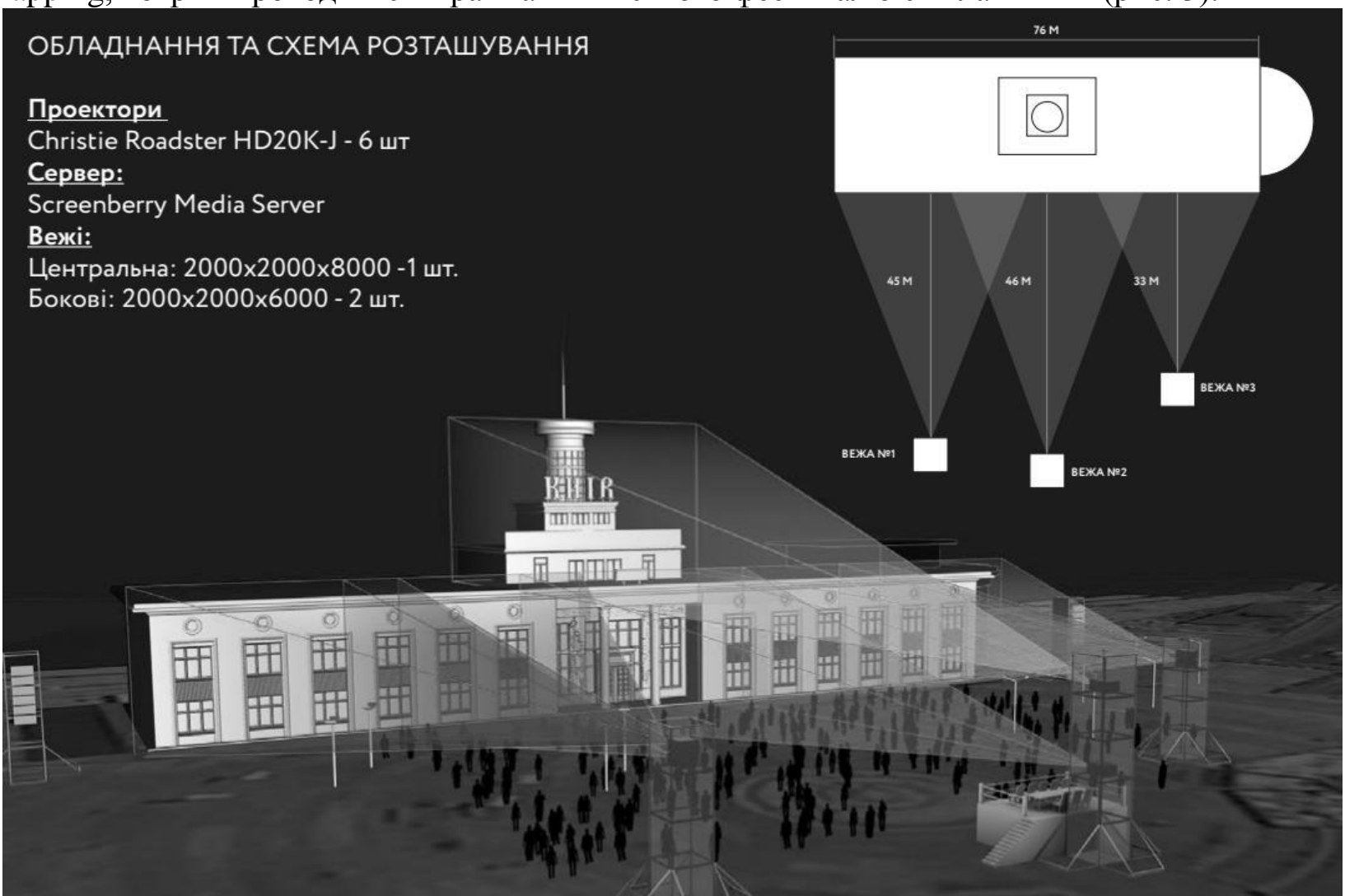

Рисунок 3. Схема розташування проекторів для освітлення будівлі Київського річкового вокзалу

Figure 3. The layout of the projectors for lighting the building of the Kiev River Station

Можливості 3D Mapping дають змогу створювати не тільки глобальні шоу або виступи артистів на світових аренах, але й влаштовувати камерні заходи та рекламні акції. Однією з них є інсталяція компанії Lifecell - "Lifecell 3D-mapping show".

Аналізуючи деякі світові події щодо використання новітніх технологій екранного мистецтва 3D Mapping, можна виокремити найбільш популярні сфери їх застосування:

- масові мультимедійні та музичні шоу - під час проведення урочистих заходів проекції здатні перетворити навколишнє середовище в заданій тематиці за допомогою кольору, сценаріїв сприйняття, а також відтворити голографічні проекції виконавців;

- дизайнерські рішення - великі можливості для інтер'єрних проектів завдяки використання кольору, візерунків, текстури, меблів та ін.;

- театральні постановки - візуалізація різних декорацій, атмосфери сюжету за допомогою різних рішень дизайну, гри світла;

- хореографічні етюди - можливість використовувати технологію в мультимедійних інтерактивних хореографічних виставах, де інтерактивність досягається завдяки редагуванню проектованого зображення на звук і рух на сцені;

- реклама - це технологія екранного мистецтва 3D-відеомеппінгу має тенденцію в майбутньому приєднатися до різновидів зовнішньої реклами, стати елементом інформаційного простору міста.

Для розвитку досліджуваної технології проводяться різноманітні фестивалі та конференції. Цінність таких фестивалів, як Московський міжнародний фестиваль «Коло світла», міжнародні фестивалі «Mapping Girona» в Іспанії та «Mapping Festival» у Женеві, фестиваль «KLF» у Києві, полягає не тільки у проекційному мультимедійному шоу для глядачів і гостей, але і в організації освітніх майданчиків, де можна поспілкуватися із 
фахівцями різних рівнів, пізнати особливості створення і застосування цієї технології в різних напрямах, набути професійного досвіду.

Висновки. Отже, екранне мистецтво нового покоління здобуло в Україні широке визнання, як і у світі. Сучасній аудиторії глядачів імпонує барвистість і видовищність заходів, під час яких емоційний вплив від побаченої аудіовізуальної ілюзії надовго залишається в пам'яті. Використання художньо-технологічного аспекта у сценарнорежисерському вирішенні будь-якого заходу (театральна постановка, святкова подія на сцені та ін.) - запорука успіху і глядацької симпатії. Еволюція екранного мистецтва 3 кін. XX ст. відбувається під впливом аудіовізуальних технологій. Сучасний етап його розвитку характеризується інтеграцією та синтезом різних засобів і технологій інформаційнотехнічного прогресу в культурі і мистецтві, що знаходить своє відображення в художньоестетичній свідомості новітнього покоління, а значить - і в культурі загалом.

\section{Список використаних джерел}

1.3D Проекционное шоу ко Дню Краматорска. Promo-Promin [caŭm] URL: http://www.promo-promin.com/portfolio/item/99/. (дата звернення: 13 Червеня 2018).

2. Кліщ О. А. Особливості використання світлових проекцій на об'єктах міського середовища. Вісник Одеської державної академії будівництва та архітектури, 2014. Вип. 54. C. 164-169. URL: http://nbuv.gov.ua/UJRN/Vodaba_2014_54_30. (дата звернення: 13.06.2018)

3. Ландер И. Г. Видео-маппинг как новая форма творчества, его виды и возможности. В мире науки и искусства: вопросы филологии, искусствоведения и культурологии: сб. ст. по матер. XI междунар. науч.-практ. конф. Ч. 2. Новосибирск: СибАК, 2012. С. 50-53.

4. Мальцева Е. В. Развитие аудиовизуальной культуры студенческой молодежи в условиях клубного объединения: дис. ... канд. пед. наук. Челябин. гос. акад. культуры и искусств. Челябинск, 2013. 194 с.

5. Михайлов Л. Н. Технические средства оформления современного эстрадного зрелища как эстетический феномен. Москва: Рос. акад. театр. искусств, 2007. 40 с.

6. Новые аудиовизуальные технологи / Отв. ред. К. Э. Разлогов. Москва : Едиториал УPCC, 2005. $481 \mathrm{c}$.

7. Познин В. Ф. Экранное творчество: современные технологии. Вестник Тамбовского университета. Тамбов, 2008. №7. С. 425-428.

8. Усов Ю. Н. В мире экранных искусств. Москва: SvR-Аргус, 1995. 224 с.

\section{References}

1. 3D Proektsionnoe shou ko Dnyu Kramatorska [3D projection show for the Kramatorsk Day]. Promo-Promin, [online] Available at: http://www.promo-promin.com/portfolio/item/99/. [Accessed 13 June 2018].

2. Klishch, O. (2014). Osoblyvosti vykorystannia svitlovykh proektsii na obiektakh miskoho seredovyshcha [Features of the use of light projections on objects of the urban environment]. Visnyk Odeskoi derzhavnoi akademii budivnytstva ta arkhitektury, [online] issue 54, pp 164-169. Available at: <http://nbuv.gov.ua/UJRN/Vodaba_2014_54_30> [Accessed 13 June 2018].

3. Lander, I., Kubakh, A. (2009). 'Video mapping as a new form of creativity, its kinds and possibilities'. Sibirskaya assotsiatsiya konsul 'tantov. Zaochnye nauchno-prakticheskie konferentsii [The Society of Professional Consultants of Siberia], [online] Available at: <http://sibac.info/index.php/2009-07-01-10-21- 16/2661-2012-05-21-07-38-11> [Accessed 13 June 2018].

4. Mal'tseva, E. (2013). Razvitie audiovizual'noi kul'tury studencheskoi molodezhi v usloviyakh klubnogo ob'edineniya [The development of audiovisual culture of student youth in the conditions of club association]. D.Ed. Chelyabinsk State Academy of Culture and Arts.

5. Mikhaylov, L. (2007). Tekhnicheskie sredstva oformleniya sovremennogo estradnogo zrelishcha kak esteticheskii fenomen [Technical means of designing a contemporary variety show as an aesthetic phenomenon]. Moscow: RATI. 
ISSN 2410-1176 (Print) Вісник КНУКіМ. Серія Мистецтвознавство. Вип. 39. ISSN 2616-4183 (Online)

6. Razlogov, K. ed. (2005). Novye audiovizual'nye tekhnologii [New audiovisual technologies]. Moscow: Editorial URSS.

7. Poznin, V. (2008). Ekrannoe tvorchestvo: sovremennye tekhnologii [Screen arts: modern technologies]. Vestnik Tambovskogo universiteta, no.2, pp. 425-428.

8. Usov, Yu. (1995). V mire ekrannykh iskusstv [In the world of screen arts]. Moscow: SvR-Argus.

(C) Доколова А. С., 2018

Стаття надійшла до редакиії: 31.08.2018

УДК 792.05:351.858:7.097

\author{
Donchenko Nataliia, \\ Honored Artist of Ukraine, \\ Kyiv National University of Culture and Arts \\ 36, Y. Konovaltsia St., Kyiv, Ukraine, 01133 \\ https://orcid.org-0000-0003-1484-6800, \\ donchenko.natal@gmail.com
}

\title{
MODERN COMEDY SHOWS ON THE UKRAINIAN STAGE: THE CONCEPT OF IDEA AND OPERATIVE SIGNS
}

The purpose of the article is to highlight the conceptual requirements for the creative idea of the director of modern comedy show programs; to characterize the operative features of comedy acts; to justify the principles of the genre layout of these forms; to systematize the main components of the professional competencies of the director and performer. The research methodology consisted in the application of art-historical, functional, analytical and systematic methods of research into modern comedy shows on the Ukrainian stage, their professional creation according to the laws of theatrical art; the analysis of the main requirements for the concept of the data regarding the productions and acts as part of a holistic performance; structuring professional competencies of the director and performer. The scientific novelty of the work lies in the first attempt to systematize the main components of professional competencies of stage directors and actors, identify the operative features of a comedy act, and develop conceptual requirements for the creation of comedy shows. Conclusions. As a result of the study, it can be concluded that the authors, producers and performers of modern comedy show programs need to adhere to professional competencies and be sure to fulfill the main tasks of acting in their artistic activity onstage, taking into account the operative signs of the genre layout of the act and performance in general.

Key words: satirical comedy; comedy show program; director; performer; act; directorial device; professional competencies; operative features; concept of idea.

Донченко Наталія Петрівна, Заслужений діяч мистецтв Украӥни, Київський національний університет культури і мистецтв, вул. С. Коновальия, 36, Київ, Украйна дійові ознаки

Сучасні гумористичні шоу-програми на естраді України: концепція задуму та

Мета роботи. Висвітлити концептуальні вимоги до творчого задуму режисерапостановника сучасних гумористичних шоу-програм, надати характеристику дійовим ознакам комедійних номерів, обгрунтувати принципи жанрового плану даних форм та систематизувати основні складові професійних компетенцій режисера і артиста естради. Методологія дослідження полягає у застосуванні мистецтвознавчого, функціонального, аналітичного, системного методів дослідження сучасних гумористичних шоу-програм на естраді України, їх професійного створення за законами сценічного мистецтва, здійснення аналізу головних вимог щодо концепції даних вистав та номеру як складової цілісного дійства, та структуризації професійних компетенцій режисера і артиста. Наукова новизна. Вперше систематизовані основні складові професійних компетенцій режисера і артиста 